\title{
Preferences of lame cows for type of surface and level of social contact in hospital pens
}

\author{
M. B. Jensen, ${ }^{* 1}$ M. S. Herskin, ${ }^{*}$ P. T. Thomsen, ${ }^{*}$ B. Forkman, $\dagger$ and H. Houe $\dagger$ \\ *Department of Animal Science, Aarhus University, AU-Foulum, Blichers Allé 20, DK-8830 Tjele, Denmark \\ †Department of Large Animal Sciences, University of Copenhagen, Grønnegårdsvej 8, DK-1870 Frederiksberg C, Denmark
}

\section{ABSTRACT}

To investigate preferences of lame cows for flooring and level of social contact, 37 lame, lactating dairy cows (diagnosed with sole ulcer or white line disease) were housed individually for $6 \mathrm{~d}$ in experimental hospital pens, where they could choose between 2 equally sized areas $(6 \mathrm{~m} \times 4.5 \mathrm{~m})$ with either deep-bedded sand or a rubber surface. On both surfaces, cows could choose between 2 equally sized areas either near or away from heifers in a neighboring group pen. Cows spent more time lying on the deep-bedded sand than on the rubber surface (870 vs. $71 \mathrm{~min} / \mathrm{d}$ ), whereas they spent less time upright (standing or walking) on the sand than on the rubber surface (180 vs. $319 \mathrm{~min} / \mathrm{d}$ ). In addition, cows spent less time self-grooming on the sand than on the rubber surface (2.2 vs. $4.7 \%$ of time spent upright). With regard to level of social contact, cows spent more time near the neighboring heifers than away from them; this was true both while lying (565 vs. $374 \mathrm{~min} / \mathrm{d}$ ) and upright (276 vs. $223 \mathrm{~min} / \mathrm{d}$ ). Self-grooming was seen significantly more near neighboring heifers than away from them ( 4.8 vs. $3.3 \%$ of time spent upright). When lying, cows more often positioned themselves in areas of the pen where they could maintain visual contact with neighboring heifers. Lame cows with sole ulcers or white line disease preferred deep-bedded sand for lying, and preferred to perform self-grooming while on the rubber surface. Similarly, they preferred to lie and to perform self-grooming while positioned near animals in a neighboring pen. These results suggest that provision of a deep-bedded lying area in hospital pens is important to the welfare of lame cows. We found no evidence of isolation-seeking behavior in animals with these diagnoses (and no systemic symptoms) while they were kept in individual hospital pens.

Key words: bedding, behavior, flooring, lameness, social contact

Received December 7, 2014.

Accepted March 26, 2015.

${ }^{1}$ Corresponding author: MargitBak.Jensen@anis.au.dk

\section{INTRODUCTION}

Lameness due to hoof disorders is prevalent in modern dairy production, and the associated pain and discomfort represent a serious threat to dairy cow welfare (Whay, 2002; Thomsen et al., 2012). Today, a large proportion of dairy cows are housed in freestall systems with concrete floors in the alleys, and within such systems, lame dairy cows have been shown to move less (Walker et al., 2008), lie for longer (Chapinal et al., 2009; Ito et al., 2010; Thomsen et al., 2012), and spend less time feeding (González et al., 2008; Gomez and Cook, 2010) compared with nonlame cows.

In recent years, increasing emphasis has been put on keeping sick or injured farm animals under special conditions, such as hospital pens, to mitigate negative effects of the pathological condition on animal welfare, as well as to facilitate recovery (Weary et al., 2009). For instance, when kept on pasture, lame cows showed a faster recovery to normal locomotion scores than corresponding lame cows kept in freestall housing (Hernandez-Mendo et al., 2007). This emphasizes the importance of the environment for the management of sick animals, and flooring, as well as the surface and structures of the freestalls, is a central feature of the lame cow's environment. In stalls, healthy dairy cows preferred soft surfaces, such as deep-bedding of sand or straw, over harder mattresses or mats (e.g., Tucker et al., 2003). Furthermore, the use of rubber flooring in the alley increased cows' stride length (Telezhenko and Bergsten, 2005), and rubber flooring increased time spent at the feed manger (Fregonesi et al., 2004; Tucker et al., 2006). However, studies on the flooring preferences of lame cows in hospital pens are lacking.

Another important aspect of dairy cow housing is the level of social contact. Cattle are social animals and generally stressed by isolation (Herskin et al., 2004). However, during the initial $3 \mathrm{~d}$ after calving, sick dairy cows actively sought isolation to a greater extent than healthy control cows (Proudfoot et al., 2014). In addition, cows diagnosed with uterine infections engaged in fewer social interactions and avoided competition for food (Huzzey et al., 2007), which could 
have been caused by reduced social motivation, reduced competitive ability, or reduced appetite. Lame dairy cows have been shown to increase feed intake per time unit (González at al., 2008), suggesting that reduced feed intake in lame cows is more likely due to reduced competitive ability or reduced social motivation, rather than reduced appetite. However, motivational studies of lame cows are necessary to investigate whether lame cows are motivated to isolate as such, or just choose isolation to avoid competition or to protect the injured body parts. If lame cows do not seek isolation, then the use of group hospital pens with minimal competition for resources may be preferable to individual hospital pens.

The aim of the present experiment was to investigate (1) floor surface preferences of lame cows; and (2) whether lame cows seek social isolation in a situation without competition for resources and without a need to protect the injured body part from conspecifics. Such knowledge is useful for development of guidelines for the housing of lame cows.

\section{MATERIALS AND METHODS}

\section{Experimental Animals and Inclusion Criteria}

Forty-two lame, lactating Holstein dairy cows from the resident herd at the Cattle Research Centre at Aarhus University (AU-Foulum, Denmark), were included in the experiment. The cows were selected from among all lactating cows of the 125-cow herd. During the study period, all lactating cows were locomotion scored weekly (Monday afternoon) when returning from the milking parlor. The cows identified as lame [locomotion score 4 on a scale from 1 (normal gait) to 5 (severely lame); Thomsen et al., 2008] were clinically examined in a hoof-trimming chute the next morning and included in the experiment, if they (1) were diagnosed with a horn-related hoof lesion (sole ulcer or white line disease); (2) were not diagnosed with any other disease (and not treated with analgesics or any other medication); and (3) were more than $14 \mathrm{~d}$ after calving. Cows diagnosed with sole hemorrhages were not included in the experiment unless they were also diagnosed with white line disease or sole ulcer. If more than 4 lame cows fulfilled the above inclusion criteria in a particular week, the 4 youngest cows were selected for the experiment. If fewer than 4 lame cows fulfilled the inclusion criteria, nonlame, nonexperimental cows (locomotion score 1 and otherwise healthy) entered the experiment to fill the 4 experimental pens (see below) and ensure a constant social environment in the experimental barn. All lame cows were locomotion scored when exiting the experiment $1 \mathrm{wk}$ later, and cows with a locomotion score of 1 or $2(n=5)$ were excluded from the experiment, leaving 37 experimental cows in the data set. Exclusion of cows with a locomotion score of 1 or 2 when exiting the experiment ensured that all experimental cows had been lame (locomotion score 3 or 4) throughout the 6-d experimental period, while they were kept in the experimental pens (when exiting the experiment, 18 cows had a locomotion score of 3 , and the remaining 19 had a locomotion score of 4). The 37 lame experimental cows in the final data set were 8 first-parity cows, 17 second-parity cows, and 12 third- or later-parity cows. The BW of these experimental cows, when moved to the experimental pens, averaged 612 (range 505-746) kg. The experiment was completed within $15 \mathrm{wk}$ in the period from September to December 2013.

\section{Housing, Feeding, and Management}

Before the experimental period, the cows were loose housed in a barn with a slatted concrete floor and freestalls fitted with 30-mm-thick rubber mattresses. Prior to the experimental period, the cows were milked twice daily in a herringbone milking parlor. Before and during the experiment, cows were fed a TMR for ad libitum intake with a forage-to-concentrate ratio of 60:40 (\% DM basis).

During the experimental period, cows were housed individually in 1 of 4 identical experimental hospital pens placed in the same room. The placing of the pens ensured visual contact between the 4 experimental cows as well as 4 neighboring heifers; each experimental cow could obtain physical contact with 2 of the neighboring heifers over the fixture separating the hospital pen and the heifer group pen (Figure 1).

Each experimental hospital pen measured $9 \times 6 \mathrm{~m}$ and consisted of 2 equally sized $(4.5 \mathrm{~m} \times 6 \mathrm{~m})$ parts. The floor of one part of the pen was covered by 30 $\mathrm{cm}$ of sand (Kosand brand; Dansand, Brædstrup, Denmark; mean grain size $0.322 \mathrm{~mm}$ ) and the floor of the other part was covered by a rubber mat [Kura Flex, Kraiburg, Tittmoning, Germany; a 19-mm-thick, pebbled-surface rubber mat with 5 -mm studs on the lower side (24 mm including 5-mm studs)]. The sand was held in place by a frame made of wooden boards. To ensure equal levelling of the 2 floor surfaces, the rubber mat was fitted on plywood on top of hard core within another wooden frame.

Each of the 2 pen parts defined by the floor surface could be further divided into 2 equally sized areas, one defining an area near the group pen holding the neighboring heifers and the other defining an area further away from the neighboring heifers. Thus, four $4.5-\times$ 3-m rectangles were defined as "sand near," "sand far," 


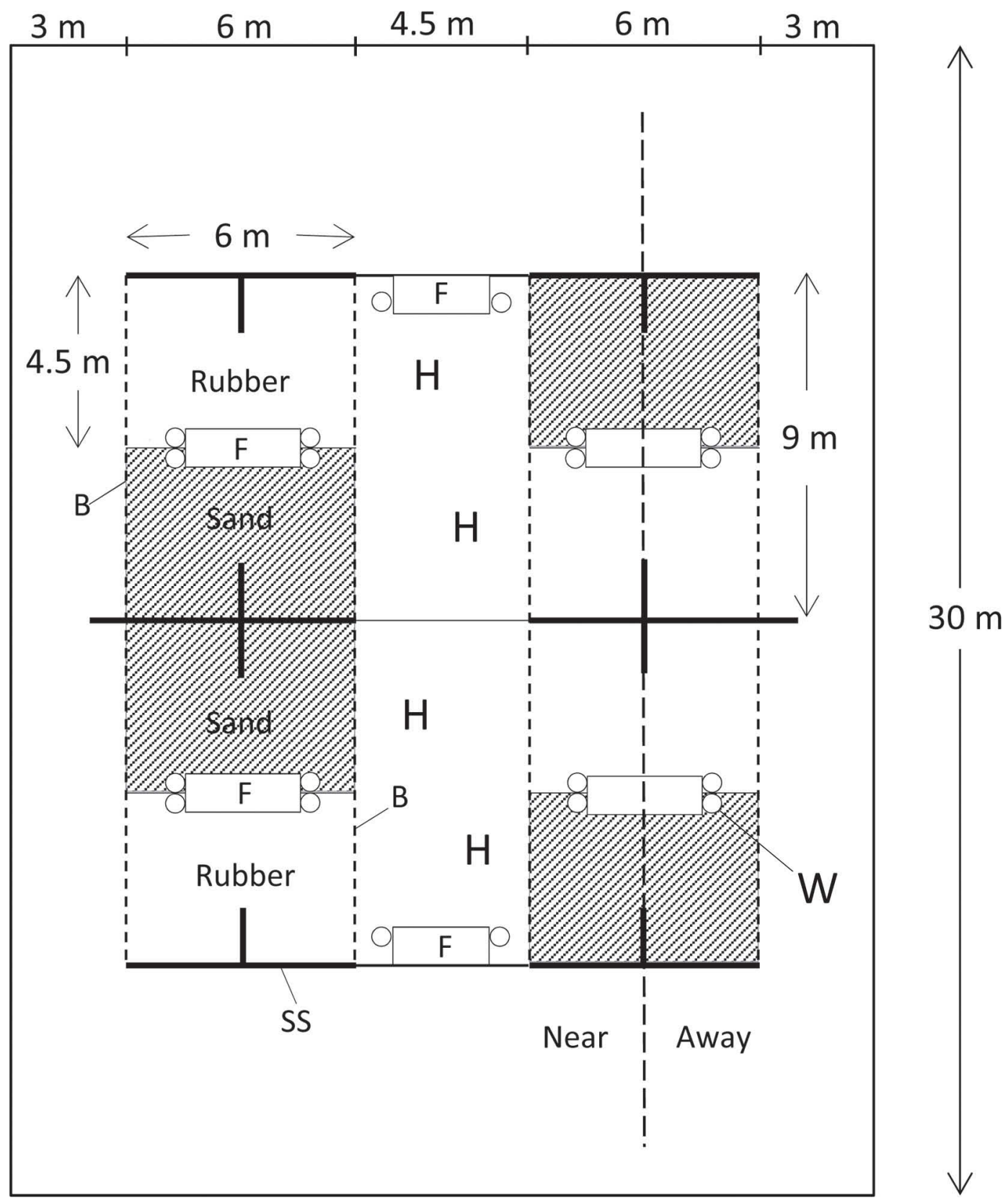

Figure 1. A schematic illustration of the experimental barn, including the 4 experimental hospital pens. Each of the 4 pens had 2 equally sized areas $(6 \mathrm{~m} \times 4.5 \mathrm{~m})$, one with sand (30-cm-deep sand, hatched areas) and one with a rubber surface (24-mm-thick rubber mat including 5 -mm studs, unhatched). Each of these 2 areas was further divided into 2 equally sized areas $(3 \mathrm{~m} \times 4.5 \mathrm{~m})$; one near to the neighboring heifers $(\mathrm{H})$ and one away from the neighboring heifers (as indicated by the vertical hatched line (- - -) creating 4 rectangles (sand near, sand away, rubber near, rubber away). A 1.5-m-wide opaque barrier placed perpendicularly to the end wall of the pen created a $1.5 \times 3 \mathrm{~m}$ corner, where the experimental cow could isolate visually from the neighboring heifers. The end walls of all 4 experimental hospital pens were solid sides (SS), whereas the sides of the pen were made from vertical tubular steel bars (B). A 3-m-long feed manger (F) was placed centrally in the pen along with 4 water bowls (W), one in each corner of the feed manger.

"rubber near," and "rubber far," respectively (Figure 1). A 1.5-m-wide barrier placed perpendicular to the end wall on each surface created 2 corners, each occupying one-eighth of the pen, where an experimental cow could isolate visually from the neighboring heifers. The end walls of all 4 experimental hospital pens were plywood, and the sides were made of vertical tubular steel bars (diameter: $2.5 \mathrm{~cm}$; distance between bars: $10 \mathrm{~cm}$ ). A 3 -m-long feed manger was placed centrally in each pen and feed was accessible from both floor surfaces. Four 
water cups were placed by the feed manger, 1 in each of the 4 rectangles (sand near, sand far, rubber near, and rubber far), and provided water for ad libitum intake.

In the experimental hospital pens, feed was provided daily between 0600 and $0700 \mathrm{~h}$ and topped up between 1600 and $1700 \mathrm{~h}$. Any feed refusals were weighed and discharged before morning feeding. Daily feed intake was calculated and averaged over the 6-d experimental period. Feed intake was on average 21.1 (SD 2.5) $\mathrm{kg}$ of $\mathrm{DM} / \mathrm{d}$ (range: 17.2 to $28.3 \mathrm{~kg}$ of $\mathrm{DM} / \mathrm{d}$ ).

While in the experimental hospital pens, cows were milked between 0600 and $0700 \mathrm{~h}$, and again between 1600 and $1700 \mathrm{~h}$. Rectal temperature was measured during morning milkings. The average rectal temperature on the first experimental morning was $38.3^{\circ} \mathrm{C}$ (range $37.7-39^{\circ} \mathrm{C}$ ). No temperatures above $39^{\circ} \mathrm{C}$ were detected in any of the experimental cows during the experimental period.

The barn was lit by natural as well as artificial light. Artificial light was on from 0600 to $2200 \mathrm{~h}$ and a dim light was on during the rest of the 24 -h period to make video recording possible.

The following protocol was used. After hoof examination, the 4 cows were moved to the hospital pens at $1030 \mathrm{~h}$. Before cow entry, a partition was placed on each side of the feed manger blocking the passage between the 2 parts of the hospital pen equipped with different surfaces. Until the next day at $1030 \mathrm{~h}, 2$ of the 4 cows were restricted to the part of the pen with sand floor, and the other 2 were restricted to the part with rubber floor. Subsequently, during the following $24 \mathrm{~h}$, the restriction was switched to ensure that all cows were equally familiar with both surfaces. Forty- eight hours after the introduction to the pens, these partitions were removed and each cow had free access to both surfaces for $4 \mathrm{~d}$, until Monday at $1000 \mathrm{~h}$, when she was removed from the pen.

During the experimental period of $6 \mathrm{~d}$, the pens were cleaned and the sand levelled out on a daily basis. Each week, before the introduction of new cows, the experimental pens were cleaned and new sand added when needed.

\section{Behavioral Recordings}

One video camera (Monacor, Bremen, Germany) was placed over each pen, and the view covered the entire pen. Position, posture, and behavior of each experimental cow were recorded continuously (Martin and Bateson, 2011) during the last $72 \mathrm{~h}$ of the stay in the pens. Two trained observers conducted these observations according to the descriptions presented in Table 1.

\section{Statistical Analysis}

For each cow and day, the time spent on each of the 2 surfaces (sand and rubber) and in each of the 2 social areas (near the neighboring heifers or away from them) was calculated along with the duration of each posture (lying or upright) and behavior (feeding, drinking, or self-grooming) while positioned in that particular part of the pen. The difference in time spent on sand and rubber, and the difference in time spent near and away from neighboring heifers was calculated. Subsequently, for each of the 4 combinations, averages per cow and day were calculated over the three 24 -h observation periods.

Table 1. Description of the behaviors that were recorded continuously for $72 \mathrm{~h}$ following a $72-\mathrm{h}$ acclimation period

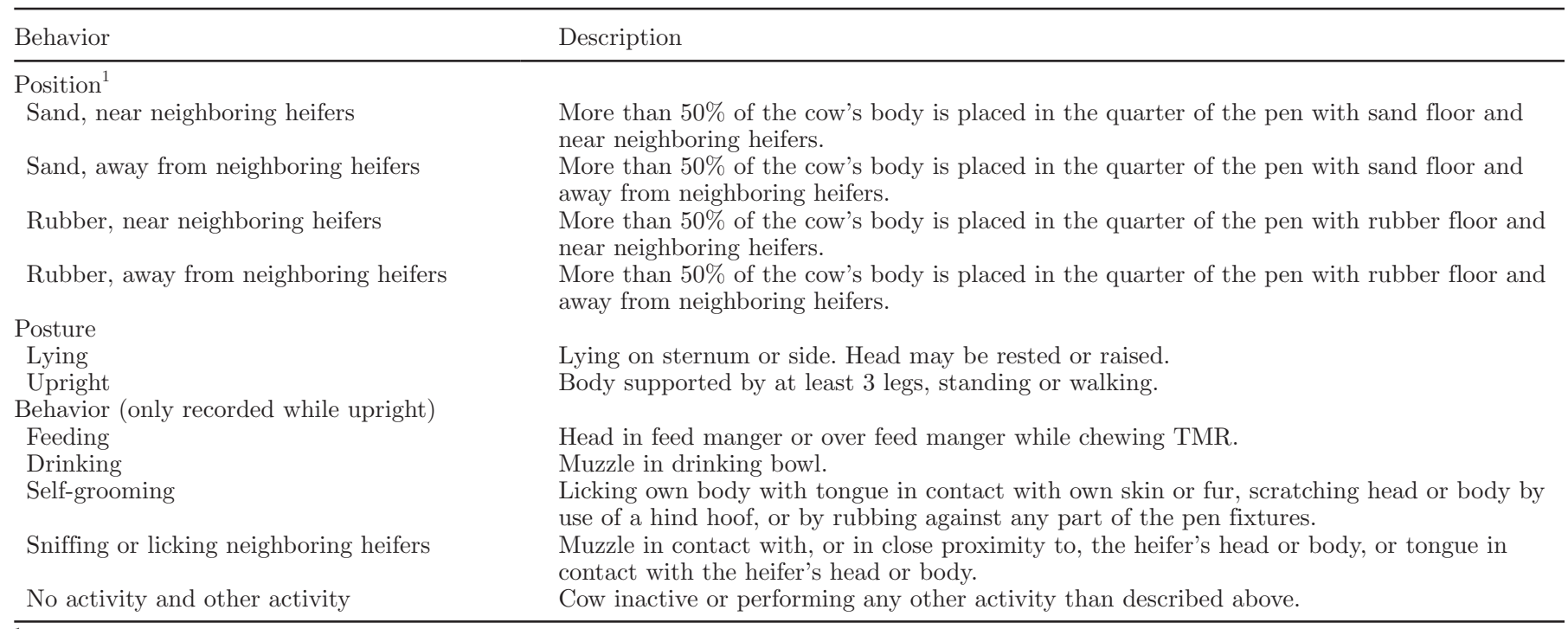

${ }^{1}$ If a cow was positioned with $50 \%$ of the body in each of 2 areas, then the position of the head determined the cow's position. 
Response variables for the statistical analyses were the difference in time spent on sand and rubber, the difference in time spent near and away from neighboring heifers, the duration of time lying while positioned in a particular part of the pen, the duration of time upright while positioned in a particular part, as well as the duration of feeding, drinking, and self-grooming, respectively, while being upright in the particular part of the pen. Finally, the duration of feeding, drinking, and self-grooming was calculated as a percentage of the time spent upright on each surface and as a percentage of the time spent upright in each social area, respectively. Except for the difference in time spent on sand and rubber, and the difference in time spent near and away from neighboring heifers, there were 2 observations per cow: 1 for each of the 2 experimental factors (surface and social area, respectively).

The difference in time spent on sand and rubber, and the difference in time spent near and away from neighboring heifers areas could not be assumed normally distributed and were analyzed by Wilcoxon signed rank sum test (Siegel and Castellan, 1988) using the PROC UNIVARIATE procedure in SAS (version 9.3, SAS Institute Inc., Cary, NC). Median time spent on sand and rubber and median time spent near and away from neighboring heifers, respectively, are given, along with interquartile ranges.

For each of the 2 experimental factors, the durations of lying, being upright, feeding, drinking, and self-grooming (the latter 3 variables were calculated as percentage of time being upright) were analyzed by a variance component analysis using PROC MIXED in SAS. The model investigating the preference for surface included the effect of surface (sand, rubber), parity (first, second, later), and the interaction between surface and parity. The model investigating the preference for social contact included the effect of social area (near or away), parity (first, second, later), and the interaction between social area and parity. The duration of self-grooming was square root transformed before analysis to meet the assumptions of normal distribution. Assumptions of normal distribution of data were checked by visual inspection of residual plots. Observer was included in initial analyses, but as this factor was never significant $(P>0.25)$, it was excluded from the final analyses.

Because of many zero observations for the duration of social behavior, the number of cows performing social behavior while positioned on each of the 2 surfaces was calculated and the effects of surface analyzed using a McNemar test using PROC FREQ in SAS.

To assess if cows would visually isolate from neighboring heifers by lying behind the barrier placed

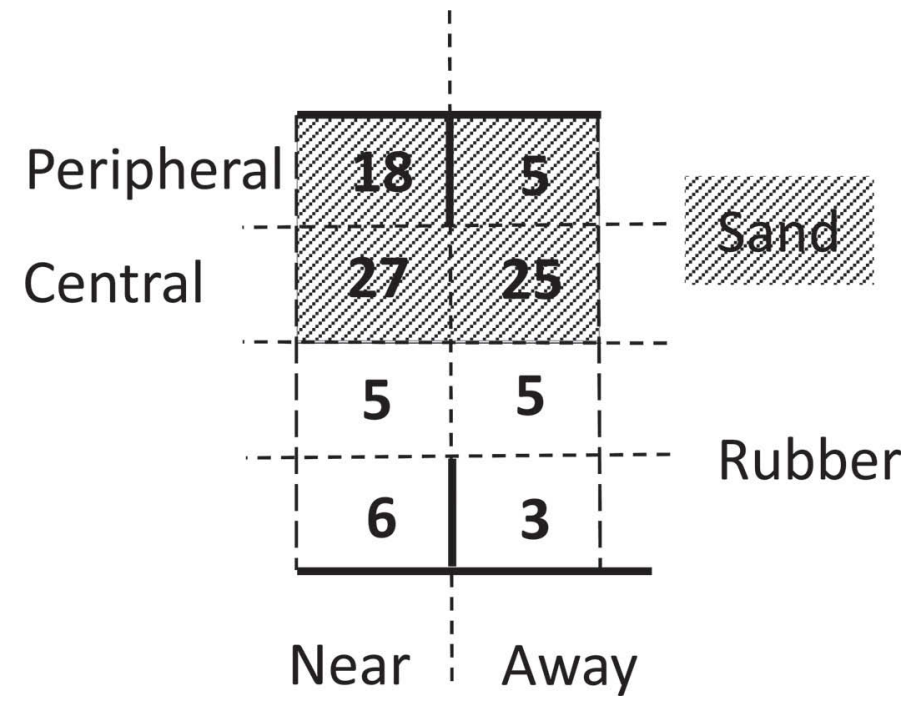

Figure 2. The number of cows that were observed to lie down at least once in each of the 8 equally sized areas (sand near peripheral, sand away peripheral, sand near central, sand away central, rubber near central, rubber away central, rubber near peripheral, rubber away peripheral). The surface was either sand (30-cm-deep sand, hatched area) or rubber (24-mm-thick rubber mat including 5-mm studs, unhatched) and the social contact was either near to heifers (near) to the left or away from heifers (away) to the right. Solid sides are indicated by thick lines, and dashed lines indicate the 8 areas. The 2 areas where visual contact with the neighboring heifers was blocked off by a plywood wall were the 2 peripheral areas away from neighboring heifers.

peripherally (perpendicular to the end wall in each surface area), the pen was divided into 8 areas, and we noted whether each of the 37 cows lay down in each of these sub-areas: "sand near peripheral," "sand away peripheral," "sand near central," "sand away central," "rubber near central," "rubber away central," "rubber near peripheral," and "rubber away peripheral" (Figure 2 ). These data were analyzed by a Chi-squared test using PROC FREQ in SAS.

\section{RESULTS}

\section{Preference for Surface}

The cows spent more time on the deep-bedded sand [1,136 (945-1,261) min/d; median (25\%-75\% quartiles)] than on the rubber surface [304 (179-494) $\mathrm{min} / \mathrm{d} ; P<$ 0.001]. On sand, cows spent the majority of the time lying, whereas on the rubber surface, they spent most of the time upright (Table 2). A larger proportion of feeding and drinking was observed when cows were upright on the rubber surface, and the same was true for self-grooming (Table 2). When the occurrence of these behavioral elements was calculated as a percentage of time spent upright on a particular surface, however, 
Table 2. Behavior of the dairy cows during the final $72 \mathrm{~h}$ in the experimental hospital pens

\begin{tabular}{|c|c|c|c|c|c|c|}
\hline Behavior & Rubber & Sand & $\mathrm{SED}^{1}$ & Total & $P$-value & Preference \\
\hline Lying & 71 & 870 & 82.6 & 941 & 0.001 & Sand \\
\hline Upright & 319 & 180 & 48.9 & 499 & 0.008 & Rubber \\
\hline Feeding & 177 & 97 & 25.7 & 274 & 0.004 & Rubber \\
\hline Drinking & 17.6 & 9.0 & 2.90 & 26.6 & 0.005 & Rubber \\
\hline Self-grooming ${ }^{2}$ & $3.70(13.7)$ & $1.68(2.8)$ & 0.38 & 16.5 & 0.001 & Rubber \\
\hline Drinking & 5.3 & 4.2 & 0.72 & & 0.13 & \\
\hline Self-grooming & 4.7 & 2.2 & 0.43 & & 0.001 & Rubber \\
\hline
\end{tabular}

${ }^{1}$ Standard error of the difference.

${ }^{2}$ Square root transformed before analysis. Back-transformed mean estimates are given in parentheses.

only self-grooming was observed significantly more on the rubber surface. No effect of surface was detected on number of animals performing social behavior directed toward the neighboring heifers (28 of 37 animals performed social behavior on rubber vs. 19 of 37 animals on sand; $P=0.18$ ).

\section{Preference for Social Contact}

The cows spent more time near the neighboring heifers $[877(542-1,094) \mathrm{min} / \mathrm{d}]$ than away from them (562 $\mathrm{min} / \mathrm{d}(347-895 ; P=0.006)$. For both lying and being upright, a larger proportion of time was spent near the neighboring heifers (Table 3). Similarly, a larger proportion of feeding and self-grooming was observed when the cows were upright near the neighboring heifers, whereas no difference was detected for drinking (Table $3)$. When the behavioral elements were calculated as a percentage of time spent upright near or away from the heifers, only self-grooming was observed significantly more often near these animals. As all social behavior by definition was performed near neighboring heifers, data for this variable are not shown. First-parity cows spent a higher percentage of time feeding near neighbors compared with second- and later-parity cows $[59.6( \pm 3.10)$, $56.8( \pm 2.12)$, and $49.3( \pm 2.53) \%$ for first, second, and later parities (mean $\pm \mathrm{SEM}) ; P=0.03$ ]

Not all 37 cows were observed to lie down in all of the 8 equally sized sub-areas of the pens. The number of cows observed to lie at least once in each of the 8 sub-areas is indicated in Figure 2. This distribution was significantly different from random [Chi-squared test ( df $=7), P<0.001]$, because more cows were observed to lie in the sand areas that allowed visual contact with neighbors (sand near peripheral, sand near central, and sand away central).

\section{Effects of Parity}

An effect of parity was found for the percentage of time spent feeding $[56( \pm 3.5), 55( \pm 2.5)$, and 46 $( \pm 2.8) \%$ for first-, second-, and later-parity cows (mean $\pm \mathrm{SEM}) ; P=0.03]$. No other effects of parity and no interactions between parity and surface type or between parity and social condition were detected for any of the variables.

Table 3. Behavior of dairy cows during the final $72 \mathrm{~h}$ in the experimental hospital pens

\begin{tabular}{|c|c|c|c|c|c|c|}
\hline \multicolumn{7}{|l|}{ Posture, $\min / \mathrm{d}$} \\
\hline Lying & 374 & 565 & 88.1 & 939 & 0.04 & Near \\
\hline \multicolumn{7}{|c|}{ Behavior while upright, $\min / \mathrm{d}$} \\
\hline Feeding & 121 & 153 & 15.8 & 274 & 0.05 & Near \\
\hline Drinking & 14.4 & 12.1 & 2.48 & 26.5 & 0.35 & \\
\hline Self-grooming ${ }^{2}$ & $2.53(6.4)$ & $3.38(11.4)$ & 0.18 & 17.8 & 0.001 & Near \\
\hline Drinking & 6.4 & 4.6 & 1.00 & & 0.09 & \\
\hline Self-grooming & 3.3 & 4.8 & 0.28 & & 0.001 & Near \\
\hline
\end{tabular}

${ }^{1}$ Standard error of the difference.

${ }^{2}$ Square root transformed before analysis. Back transformed mean estimates are given in parentheses. 


\section{DISCUSSION}

The present study showed that cows suffering from lameness due to sole ulcer or white line disease preferred to lie on a surface of deep-bedded sand, whereas they preferred to perform self-grooming behavior while standing on a rubber surface.

The preference of sand for lying is in concurrence with previous studies showing that healthy dairy cows prefer to lie in stalls with deep bedding of sand or sawdust (Tucker et al., 2003), and sand or straw (Calamari et al., 2009), compared with stalls equipped with mattresses. However, lame cows appear to be more sensitive to the lying surface than do nonlame cows. For instance, in stalls with mattresses, lame cows spent less time lying than nonlame cows (Cook et al., 2004), whereas in stalls with sand, lame cows spent more time lying than did nonlame cows (Ito et al., 2010). The shorter time spent lying on the harder surface may be due to difficulties when changing position from standing to lying or vice versa (Cook and Nordlund, 2009). This in turn may be due to a reluctance to bear weight on the injured limb, thereby increasing effects of hard flooring for lame compared with nonlame animals. Whay et al. (1998) suggested that lameness might be associated with increased sensitivity to noxious stimuli, which may strengthen the argument for special protective housing for lame cows. Providing an optimal lying surface appears to be an obvious first step.

In the present study, lame cows preferred to perform self-grooming (licking and scratching) while on the rubber surface. This preference was contrary to expectation, because self-grooming requires effort to maintain balance, which may be easier for a cow on the nonslip sand surface. Hence, the lame cow's preference for self-grooming on the rubber surface requires further investigation, and future studies should investigate whether lame cows have other requirements regarding the opportunity to perform self-grooming. Previously, measures of locomotion that reflect ease of walking (walking speed, stride length, and step length) have shown that walking is easier on sand (moist sand compressed with a tractor) compared with concrete or rubber floors (Telezhenko and Bergsten, 2005). There are no studies of cow locomotion in the specific type of sand used in the present study, which was a typical sand used for stalls. One possible explanation for the preference to stand and perform self-grooming on the rubber surface may be that moving in the deep sand, which was loose, may have been more strenuous than moving on the rubber.

The difference in time spent near versus away from the neighboring heifers was less pronounced than the differences between the surfaces. However, the animals did spend more time near the neighboring heifers both when lying and standing, and also spent more time near the neighbors when performing self-grooming. It has been shown that postpartum cows with fever and diagnosed with an infectious disease (mastitis, metritis, pneumonia, or a combination) spent more time isolating behind an opaque barrier than healthy cows (Proudfoot et al., 2014), suggesting that dairy cows with a systemic disease seek isolation. The difference between the present experiment and the work by Proudfoot et al. (2014) may be that the cows in the current study did not have fever and none showed signs of systemic disease during the experimental period. Hence, isolation-seeking behavior may be specifically related to systemic diseases (Dantzer and Kelley, 2007). Thus, care must be taken not to generalize between cows with and without systemic disease as regards their social motivation and special requirements for housing. Research involving cows with localized hoof lesions and systemic disease would be beneficial for the future design and management of hospital pens for dairy cows to enhance animal welfare. Furthermore, future studies should investigate under which conditions lame cows may be housed in group hospital pens, including requirements for minimizing competition for space, feed, and water in such pens. Reduced activity is another typical behavioral response to sickness (Aubert, 1999), and lame cows have been shown to be less active than corresponding nonlame cows (e.g., Walker et al., 2008). However, this may not be due to sickness as such, but instead might reflect an attempt to guard the injured limb from pain.

The present results suggest that lame cows suffering from hoof horn lesions do not have a reduced social motivation and do not seek isolation. Thus, if lame cows are avoiding social interactions in loose housing systems (e.g., González at al., 2008), it may be due to pain and reduced competitive ability, rather than reduced social motivation per se. However, future studies comparing the social motivation of nonlame versus lame cows are needed to verify this hypothesis.

In conclusion, in a choice experiment, lame cows diagnosed with sole ulcer or white line disease showed a preference for deep-bedded sand while lying but preferred to perform self-grooming when on a rubber surface. These results suggest that lame cows with these diagnoses would benefit from housing in an environment with a deep-bedded lying area. We found no evidence of isolation-seeking behavior in lame cows.

\section{ACKNOWLEDGMENTS}

The study was financed by the Danish Animal Welfare Centre (Glostrup, Denmark). We thank the staff at the cattle research facility at AU-Foulum (Tjele, Den- 
mark) for taking care of the cows. We are grateful to Henrik Krogh Andersen for conducting the locomotion scoring, to Heidi Smith and Henrik Krogh Andersen (both Aarhus University, Tjele, Denmark) for recording the behavior from the videos, and to Anton S. Jensen, Erik L. Decker and Connie H. Middelhede (all Aarhus University) for assisting with data editing. Finally, we thank Tina Albertsen (Aarhus University) for critically reviewing the English language.

\section{REFERENCES}

Aubert, A. 1999. Sickness and behaviour in animals. Neurosci. Biobehav. Rev. 23:1029-1036.

Calamari, L., F. Calegari, and L. Stefanini. 2009. Effect of different free stall surfaces on behavioural, productive and metabolic parameters in dairy cows. Appl. Anim. Behav. Sci. 120:9-17.

Chapinal, N., A. M. de Passillé, D. M. Weary, M. A. G. von Keyserlingk, and J. Rushen. 2009. Using gait score, walking speed, and lying behavior to detect hoof lesions in dairy cows. J. Dairy Sci. 92:4365-4374.

Cook, N. B., T. B. Bennet, and K. V. Nordlund. 2004. Effect of free stall surface on daily activity patterns in dairy cows with relevance to lameness prevalence. J. Dairy Sci. 87:2912-2922.

Cook, N. B., and K. V. Nordlund. 2009. The influence of the environment on dairy cow behavior, claw health and herd lameness dynamics. Vet. J. 179:360-369.

Dantzer, R., and K. W. Kelley. 2007. Twenty years of research on cytokine induced sickness behavior. Brain Behav. Immun. 21:153-160.

Fregonesi, J. A., C. B. Tucker, D. M. Weary, F. C. Flower, and T. Vittie. 2004. Effect of rubber flooring in front of the feed bunk on the time budgets of dairy cattle. J. Dairy Sci. 87:1203-1207.

Gomez, A., and N. B. Cook. 2010. Time budgets of lactating dairy cattle in commercial freestall herds. J. Dairy Sci. 93:5772-5781.

González, L. A., B. J. Tolkamp, M. P. Coffey, A. Ferret, and I. Kyriazakis. 2008. Changes in feeding behavior as possible indicators for the monitoring of health disorders in dairy cows. J. Dairy Sci. 91:1017-1028.

Hernandez-Mendo, O., M. A. G. von Keyserlingk, D. M. Veira, and D. M. Weary. 2007. Effects of pasture on lameness in dairy cows. J. Dairy Sci. 90:1209-1214.
Herskin, M. S., L. Munksgaard, and J. Ladewig. 2004. Effects of acute stressors on nociception, adrenocortical responses and behavior of dairy cows. Physiol. Behav. 83:411-420.

Huzzey, J. M., D. M. Veira, D. M. Weary, and M. A. G. von Keyserlingk. 2007. Behavior and intake measures can identify cows at risk for metritis. J. Dairy Sci. 90:3320-3233.

Ito, K., M. A. G. von Keyserlingk, S. J. LeBlanc, and D. M. Weary. 2010. Lying behavior as an indicator of lameness in dairy cows. J. Dairy Sci. 93:3553-3560.

Martin, P., and P. Bateson. 2011. Measuring Behaviour. An Introductory Guide. Cambridge University Press, Cambridge, UK.

Proudfoot, K. L., M. B. Jensen, D. M. Weary, and M. A. G. von Keyserlingk. 2014. Dairy cows seek isolation at calving and when ill. J. Dairy Sci. 97:2731-2739.

Siegel, S., and N. J. Castellan. 1988. Nonparametric Statistics for Behavioral Sciences. McGraw-Hill, New York, NY.

Telezhenko, E., and C. Bergsten. 2005. Influence of floor type on locomotion in dairy cows. Appl. Anim. Behav. Sci. 93:183-193.

Thomsen, P. T., L. Munksgaard, and J. T. Sørensen. 2012. Locomotion scores and lying behaviour are indicators of hoof lesions in dairy cows. Vet. J. 193:644-647.

Thomsen, P. T., L. Munksgaard, and F. A. Tøgersen. 2008. Evaluation of a lameness scoring system for dairy cows. J. Dairy Sci. 91:119-126.

Tucker, C. B., D. M. Weary, A. M. de Passillé, B. Campbell, and J. Rushen. 2006. Flooring in front of the feed bunk affect feeding behavior and use of the free stall in dairy cows. J. Dairy Sci. 89:2065-2071.

Tucker, C. B., D. M. Weary, and D. Fraser. 2003. Effects of three types of free-stall surfaces on preferences and stall usage by dairy cows. J. Dairy Sci. 86:521-529.

Walker, S. L., R. F. Smith, J. E. Routly, D. N. Jones, M. J. Morris, and H. Dobson. 2008. Lameness, activity time-budgets, and estrus expression in dairy cattle. J. Dairy Sci. 91:4552-4559.

Weary, D. M., J. M. Huzzey, and M. A. G. von Keyserlingk. 2009. Board Invited Review: Using behavior to predict and identify ill health in animals. J. Anim. Sci. 87:770-777.

Whay, H. R. 2002. Locomotion scoring and lameness detection in dairy cattle. In Pract. 24:444-449.

Whay, H. R., A. E. Waterman, A. J. F. Webster, and J. K. O'Brien. 1998. The influence of lesion type on the duration of hyperalgesia associated with hind limb lameness in dairy cattle. Vet. J. 156:23-29. 